\title{
Desenvolvimento de Artefatos Digitais por Estudantes na Educação do Campo: Uma Pesquisa-Ação em Comunidades de Prática
}

\author{
Flávia M. A. Peres ${ }^{1}$, Dyego C. S. Morais ${ }^{2}$, Shany Queiroz ${ }^{1}$, Bruno Santana ${ }^{1}$ \\ ${ }^{1}$ Departamento de Educação - Universidade Federal Rural de Pernambuco (UFRPE) Rua \\ Dom Manuel de Medeiros, s/n, Dois Irmãos - CEP: 52171-900 Recife-PE-Brasil \\ ${ }^{2}$ Centro de Informática - Universidade Federal de Pernambuco (UFPE) \\ flavia.peres@ufrpe.br, moraisdcs@gmail.com, shany.queiroz@gmail.com, \\ brunosantana610@gmail.com
}

\begin{abstract}
Rural education appears contrary to the paradigm of overvaluing urbanity and promotes social changes that aim at valuing peasant peoples. In this article, we intend to present results of an action research in rural territories, in local teaching situations with DEMULTS methodology, directed to the development of digital educational artifacts, with the participation of students from these territories. As a result-tool, the configurations of utterances throughout the phases of the process indicated the production of meanings by the participants, mediated by social voices that integrate rural education, programming and design.
\end{abstract}

Resumo. A educação do campo surge contrariamente ao paradigma de supervalorização da urbanidade, promovendo transformações sociais que visem à valorização dos povos campesinos. Neste artigo, apresentam-se resultados de uma pesquisa-ação em territórios rurais, em situações locais de ensino com a metodologia DEMULTS, direcionada ao desenvolvimento de artefatos digitais educacionais, com a participação de educandos desses territórios. Como ferramenta-resultado, as configurações dos enunciados ao longo das fases do processo indicaram produção de sentidos pelos participantes, mediada por vozes sociais que integram educação do campo, programação e design.

\section{Introdução}

A atual sociedade da informação tem promovido verdadeiras transformações nas identidades culturais, como caracterizada nas leituras de Castells (1999), Bauman (2005), Hall (2011). Os territórios rurais são parte dessa grande rede global, mas a integração tecnológica às especificidades locais raramente é enfatizada. Munarim (2014) aponta que há um grande esforço de inclusão digital para escolas do campo, mas levanta uma problemática relacionada ao tipo de inclusão: se vai fortalecer o projeto dos povos do campo ou se vai ser mais um mecanismo de imposição. Neste artigo, posicionando-se nesta arena de tensões, defende-se um diálogo entre as práticas sociais de desenvolvimento de artefatos digitais e as práticas cotidianas dos povos do campo, como uma possível inclusão digital contra-hegemônica.

A educação do campo surge no Brasil como uma forma de "acelerar o processo de supressão das intensas desigualdades no tocante à garantia de direitos existentes no meio rural" [Molina 2008, p.13]. O termo educação do campo, apesar de polissêmico, uma vez que 
possui várias tendências, perspectivas e objetivos das propostas político-pedagógicas, destina-se a ser uma referência educativa para os "povos do campo" [Santos 2013]. Seu início dialoga com reivindicações de movimentos sociais que defendem um território rural, ou seja, um espaço de interação onde se realizam as diversas formas de organização do campesinato e da agricultura, compreendendo-o como espaço de vida [Fernandes 2006].

A partir da efetivação das diretrizes da educação do campo, percebe-se sua contribuição para que os sujeitos do campo possam entrar na escola e produzir significados e sentidos desde seu lugar de origem, compreendendo sua história e sua importância para a produção de riquezas materiais e culturais [Caldart et al. 2002]. No entanto, o processo de mudança de paradigma social é bastante lento, considerando-se os alcances possíveis que ainda não são realidade para os sujeitos campesinos. Nas escolas situadas em regiões rurais do país, pode-se observar um déficit no abastecimento de recursos que atendam a demandas específicas de seus territórios, bem como de recursos comuns disponibilizados para regiões urbanizadas do país [Munarim 2014].

Ao tratarmos de tecnologias digitais educacionais, da maneira como se desencadearam os processos históricos no Brasil, assim como em outros países latinoamericanos, a massiva produção e consumo desses artefatos permanece com concentração de desenvolvimento e uso em contextos urbanos [Leal 2012]. Complementando a discrepância entre territórios urbanos e rurais, dados do Instituto Brasileiro de Geografia e Estatística (IBGE) apontam que apenas $49,2 \%$ da população rural brasileira tem acesso à internet, em contrapartida aos $83,8 \%$ de usuários das regiões urbanas do país [IBGE 2018], exibindo uma grande disparidade de acesso à internet entre as regiões do Brasil. Tais desigualdades configuram-se como uma supressão de possibilidades de inclusão digital que, na contemporaneidade, apresenta-se como condição necessária para obtenção, produção e compartilhamento de conhecimento.

A pesquisa apresentada neste artigo orienta-se em direção oposta à representação social que associa tecnologias digitais, em contextos rurais, ao desenvolvimento da agroindústria e seus desdobramentos. Nesse sentido, objetiva-se compreender o processo didático de desenvolvimento de artefatos digitais educacionais com a participação de sujeitos em escolas de educação do campo. Isso implica uma abordagem sobre as tecnologias que se orienta a ideais contra hegemônicos e metodologias coerentes com a realidade da agricultura camponesa, do campesinato, em defesa de modos de vida sustentáveis.

\section{Fundamentos teórico-metodológicos}

Com base em uma perspectiva histórico-cultural em psicologia e educação [Vigotski 2001], compreende-se que os sujeitos são constituídos socialmente, em interações situadas e distribuídas entre outros sujeitos e os artefatos das atividades. A partir dessa perspectiva, o conceito de Comunidades de Prática $(\mathrm{CP})$ foi adaptado para uma metodologia didática, com potenciais aplicações em escolas do campo. Uma CP pode ser definida como um grupo de pessoas que objetiva desenvolver habilidades em torno de um interesse em comum, compartilhando práticas, negociando significados, identidades e culturas, formando assim um sistema de aprendizagem social. Os sujeitos em uma $\mathrm{CP}$ aprendem através do compartilhamento de conteúdos e experiências, transparência no uso de instrumentos e certa horizontalidade nas interações [Wenger 1998].

Falcão et al. (2017, p. 197) conceituam CP no DEMULTS como "um dos muitos núcleos nos quais as interações entre sujeitos levam à produção de conhecimento e, portanto, 
ao desenvolvimento sócio cognitivo". A finalidade de engajamento por meio dessa CP no projeto é que os educandos, iniciantes no desenvolvimento de artefatos digitais educacionais (aplicativos e jogos), possam, a partir da interação com experts no processo, apropriar-se, ativamente, de significados a respeito de seu território, e de significados relacionados a computação e design, no cruzamento dialógico entre conceitos cotidianos e científicos.

Essa base teórica fundamenta a metodologia do projeto DEMULTS, estabelecida previamente em três ciclos de pesquisa-ação no contexto urbano, sendo necessárias adaptações diante dos desafios e possibilidades em contextos de educação do campo (atualmente, em seu segundo ciclo). O DEMULTS consiste em processos de autoria-uso de artefatos digitais educacionais, em vivências escolares de Design Participativo (DP) [Ehn; Kyng 1991] e Programação pelo Usuário Final (PUF) [Lieberman et al. 2006], com efetiva participação de alunos das escolas do campo, locus da pesquisa.

Em contextos escolares, métodos de DP incluem educandos engajados no processo de criação de artefatos que estarão presentes no seu cotidiano [Baranauskas 2013]. Para as atividades do DEMULTS, a adoção do DP indica que os sujeitos efetivamente participem do desenvolvimento de artefatos digitais educacionais e não apenas sejam usuários finais representativos consultados, potencializando a convergência com as diretrizes da educação do campo, que valoriza os territórios e os conhecimentos produzidos pelos seus sujeitos por meio de metodologias participativas.

O paradigma de PUF, por sua vez, indica ferramentas e níveis de modificação de software [Lieberman et al. 2006] que permitem a programação por usuários não programadores, como os ambientes de programação visual que vêm sendo usados nos ciclos do DEMULTS (Stencyl, Scratch e App Inventor), que reduzem a preocupação com a sintaxe da linguagem de programação, favorecendo competências e habilidades em computação.

Para além dos produtos finais concebidos a partir da $\mathrm{CP}$, no presente artigo, apresentam-se configurações contextuais de enunciados entre experts (educadores, programadores, designers e técnicos agrícolas) e novatos (educandos de escolas do campo), que possibilitaram a integração entre conceitos científicos e habilidades de programação e design, somados à produção de sentidos sobre a agricultura, o campesinato e a sustentabilidade ambiental. Desta forma, identificamos as particularidades do processo discursivo durante a metodologia DEMULTS que promoveram (e como promoveram) aprendizagem na educação do campo.

\section{Metodologia}

Trata-se de uma pesquisa-ação [Thiollent 2004], na qual os/as pesquisadores/as relacionaram atividades em duas escolas situadas no município de Vicência-PE, orientadas pelas diretrizes da Educação do Campo. Após ciclos de intervenção do grupo de pesquisa DEMULTS em escolas localizadas em regiões urbanas, com resultados que apontaram para o aprimoramento de uma metodologia didática de desenvolvimento de artefatos digitais com a participação de alunos do ensino médio [Peres et al. 2020], o grupo estendeu-se como DEMULTS-Campo. Em seu primeiro ciclo (2017-2018), o DEMULTS-Campo atuou em uma instituição de ensino situada em território rural, mas na região metropolitana de Recife-PE, com fortes contornos urbanos, e ainda pouco alinhada às diretrizes da educação do campo.

No presente ciclo (2019-2020), o DEMULTS-Campo desdobrou sua metodologia para contextos escolares situados na zona rural do estado, cujos projetos político-pedagógicos 
estão fortemente orientados pelas diretrizes da educação do campo. O alinhamento das escolas com as diretrizes da educação do campo é efetivado pela secretaria de educação do município, com capacitações frequentes e reuniões semanais, das quais participam técnicos agrícolas atuantes nas escolas e suas coordenadoras pedagógicas. Duas escolas (A e B) foram indicadas como potenciais para a realização do DEMULTS-Campo em Vicência-PE.

Em cada escola, inicialmente, 30 estudantes foram escolhidos pelas coordenadoras, que deveriam primar por maior diversidade de perfis possíveis, variando-se em gênero sexual, territórios de origem, desempenho em sala de aula, rendimento de aprendizagem, de modo a formar um grupo misto e plural. Os encontros com as turmas tinham duração de 2 horas, ocorrendo uma vez por semana, no período entre agosto/2019 e setembro/2019, e duas vezes por semana, entre outubro/2019 e meados de dezembro/2019. Em março e abril aconteceriam os testes e apresentação dos artefatos desenvolvidos às comunidades escolares, mas estas etapas foram suspensas em decorrência da pandemia da COVID-19.

A equipe nuclear que atuou na pesquisa-ação, com frequência regular ao longo do processo e mediadora das atividades propostas, como experts, contou com cinco principais integrantes: dois pesquisadores atuando principalmente no eixo da programação, duas pesquisadoras com foco em educação e processos de aprendizagem e uma colaboradora com expertise em design. $\mathrm{Na} \mathrm{CP}$ do DEMULTS-Campo em cada escola, outros experts participaram, vinculados institucionalmente às escolas, foram eles os técnicos e as coordenadoras, com vozes significativas para a produção de sentido sobre os territórios. A interação novatos-experts e novatos-novatos, na CP do DEMULTS, em escolas do campo, objetiva o engajamento do grupo tanto para participação em práticas discursivas do contexto de desenvolvedores/as, programadores, designers e outros, quanto em práticas dos territórios rurais, relacionadas aos conceitos e aspectos curriculares que são previstos com intencionalidade pedagógica.

Inicialmente, nos ciclos transcorridos até 2017, as etapas do projeto consistiam em Apresentação e Seleção; Aulas e Workshops de programação e design; Análise de Jogos; Ideação; Produção e Testes dos artefatos digitais. No entanto, para esta fase do projeto, DEMULTS-Campo, foram necessárias algumas alterações em decorrência do locus de pesquisa (escolas da zona rural alinhadas às diretrizes da educação do campo), como são descritas a seguir e serão evidenciadas nas análises e resultados.

No primeiro ciclo do DEMULTS-Campo, aplicado em escola do campo na região metropolitana de Recife-PE, foi inserida a etapa de Delimitação conceitual, em que os educandos escolhiam entre opções de conteúdos a serem trabalhados nos jogos. Naquele momento, com base nas regularidades discursivas, verificou-se a eficácia de um momento inicial no processo, ao qual denominamos Imersão, em que os estudantes apropriam-se de discussões e problemáticas típicas de seus territórios, imersos em situações práticas, potencializando a relação entre conceitos científicos e conceitos cotidianos. No primeiro ciclo isso se deu a partir da construção de uma composteira. Além disso, verificou-se também que muitos conceitos trabalhados nas aulas e workshops eram esquecidos ou negligenciados, sendo necessário na fase de Ideação e Produção serem retomados para resolução de problemas reais. Com isso optou-se pela remoção da etapa de aulas e workshops, de modo a favorecer a construção do conhecimento na prática, conforme demanda das etapas seguintes.

Entre o primeiro e o segundo ciclo no contexto campesino, a principal mudança foi a ampliação da troca de saberes. A fim de fortalecer o projeto sustentável da educação do campo, na etapa de imersão do primeiro ciclo foi necessário construir uma composteira com 
os educandos, pois eles não tinham experiência prévia com atividades de manuseio com a terra. Já no segundo ciclo, haviam hortas e composteiras nas escolas e os educandos já tinham experiência prévia no manuseio com a terra, de forma a lhes possibilitar que realizassem entrevistas com seus responsáveis para se apropriarem da história dos territórios que ocupam. Além disso, enquanto no primeiro ciclo a delimitação conceitual se deu antes da imersão, de forma democrática com livre escolha entre opções pré-estabelecidas; no segundo ciclo ocorreu após a imersão, de forma participativa, construindo coletivamente a definição das temáticas com bastante diálogo, a partir dos saberes prévios dos educandos.

Apesar da compreensão de que a metodologia DEMULTS, em seus ciclos de pesquisa-ação, necessariamente será transformada, por estar em constante aprimoramento, no diálogo com os sujeitos em seus territórios, as demandas do novo contexto de aplicação da pesquisa, nas escolas situadas na zona rural de Vicência-PE, ocasionaram disrupções nas ações dos pesquisadores, advindos da zona urbana, e reflexões acerca do processo, com impacto sobre suas percepções dos territórios em foco. Portanto, para esta nova fase do projeto, as etapas da metodologia DEMULTS foram organizadas em: Convite $e$ Apresentação, Imersão, Delimitação Conceitual, Ideação, Produção e Testes, as quais serão melhor explicadas a seguir, já permeadas pelas análises dos dados.

A coleta dos dados foi orientada etnograficamente, utilizando-se de recursos diversos da etnografia: observação participante, diários de campo, entrevistas semi-estruturadas, videografias e fotografias. A sistematização e análise dos dados obtidos ocorreu a partir de uma combinação utilizando a Análise Interacional e videográfica, proposta por Jordan \& Handerson (1995) e Goodwin (2000), e a Análise Dialógica do Discurso, baseada em princípios estabelecidos a partir do círculo bakhtiniano [Bakhtin 2004; Medina 2013], com foco nos enunciados e suas relações ideológicas com os contextos de suas emergências.

\section{Análises e resultados}

A unidade analítica neste trabalho focaliza os enunciados linguísticos dos participantes, que se apresentam nos contextos de ação, com um todo de sentido. Cada enunciado analisado guarda certo acabamento, mas possui uma incompletude, pois seus autores pressupõem alcances discursivos complementares (nem sempre concretizados). Todo enunciado é permeado ideologicamente por vozes sociais, as quais configuram uma orientação de sentido, captada na interação. Enunciados podem aparecer concretamente como palavras escritas ou faladas pelos participantes, frases, gestos, registros ou marcas diversas, como por exemplo, desenhos em papel nos contextos de interação ou ícones e mensagens na interface de um artefato digital, como campo semiótico. A partir da Análise Dialógica do Discurso, os resultados são apresentados a seguir, organizados pelas fases do processo DEMULTSCampo, aplicado em seu segundo ciclo.

Seleção/Convite e Apresentação - Diferente das outras aplicações do projeto, em que se apresentava o projeto e, com o uso de questionários, transcorria a seleção dos participantes, no ciclo atual, houve um convite realizado pela coordenação das próprias escolas a educandos com perfis variados, seguindo-se a isso uma apresentação do projeto, aos convidados. A mudança foi um requisito das coordenações das escolas, devido aos encontros serem no contra-turno escolar e elas precisarem contactar os responsáveis dos educandos e providenciarem merendas para permanência nas escolas, antes das atividades iniciarem na escola. Com isso, solicitou-se uma pluralidade de perfis dos indivíduos participantes, amparada pelo conhecimento das coordenadoras sobre os sujeitos. 
No primeiro encontro dos/das pesquisadores/as com os educandos convidados, em uma roda de diálogo, foi explicada a proposta desde seus objetivos e temática, até informações mais técnicas sobre a pesquisa, com aspectos éticos, como o Termo de Consentimento Livre e Esclarecido que os estudantes levaram para assinatura de seus pais (exceto um educando, maior de 18 anos, que assinou o TCLE no local). Os enunciados que pautavam as relações sobre a pesquisa estabeleceram-se, nos encontros iniciais, de forma diferenciada na CP, pois além de vozes dos experts em papéis de designers e programadores, esses experts também mediavam as interações como pesquisadores. Ao longo das fases, ações como filmagens, fotografias e notas em campo, configuravam os enunciados com contornos discursivos de pesquisa. Sobre a prática de desenvolvimento propriamente dita, nesta fase, os educandos realizaram, a partir de uma dinâmica de grupo de criação de desenhos, registros gráficos sobre o que compreendiam por tecnologias, tecnologias digitais e seus usos cotidianos.

Os enunciados produzidos pelos educandos, em seus desenhos e falas, indicaram a presença de celulares, computadores e também eletrodomésticos variados em seus cotidianos, bem como práticas de uso de artefatos digitais em seus territórios. Apesar de dificuldades evidenciadas, principalmente na escola A, na formulação de enunciados acerca do que seria tecnologia, a maioria dos educandos relacionou o termo tecnologia a artefatos digitais, excluindo tecnologias diversas produzidas ao longo da história humana e que permeiam os territórios do campo, com saberes de práticas ancestrais de agricultores, por exemplo. Alguns enunciados dos experts na atividade buscaram uma reflexão sobre esse aspecto.

Nesta fase, foi estabelecido um contato inicial entre experts (time de pesquisadores desenvolvedores) e novatos (educandos), e explicitados alguns acordos sobre participação, sistemáticas de encontros semanais, cronograma e outros enunciados dos experts que favorecessem o conhecimento sobre o projeto DEMULTS. Neste contato inicial, alguns enunciados nas configurações contextuais da escola A, com proeminência para o campo do gesto e da fala, indicaram mais dúvidas e curiosidades sobre o projeto, por parte dos novatos, do que uma motivação concreta para estar ali, no que viria a ser uma CP de desenvolvedores de tecnologias digitais. Também foram percebidas algumas compreensões equivocadas, muitas delas provavelmente originadas do encontro prévio, com a coordenação, que realizou o convite para participarem do projeto. De todo modo, evidenciados mais claramente na escola B, encontram-se enunciados dos novatos que permitiram inferir a existência de uma boa motivação inicial para participar do projeto DEMULTS. Houve predominância de enunciados com autoria dos experts em educação programação e design (pesquisadores) sobrepondo-se aos dos novatos (educandos), direcionando a atividade e conduzindo o processo nessa fase, não sendo observada ainda uma horizontalidade nas ações, como idealizada. No entanto, já se percebeu uma configuração contextual nos enunciados dos experts que era eminentemente provocativa e indagativa, esperando a resposta de outros sociais, os novatos, para que complementassem a cadeia de enunciados. Desse modo, configuraram-se enunciados que convidavam à participação legítima dos novatos, embora esta participação ainda fosse periférica, no processo interativo desta fase.

Imersão - Nesta fase, a fim de compreender mais sobre o cotidiano e os problemas enfrentados pelos educandos, além de orientar para um olhar reflexivo sobre suas vivências como cidadãos do campo, foi proposta uma atividade pelos experts em educação, programação e design (pesquisadores), a ser realizada pelos novatos em grupos menores. A atividade consistia no relato sobre um evento, estruturado como história em quadrinhos, em 
que fossem registradas, nessas histórias, situações típicas de seus cotidianos no campo. A estrutura das histórias em quadrinhos possui bastante semelhança com o formato dos storyboards que, posteriormente, seriam realizados e refinados para guiar o processo de criação dos artefatos digitais no DEMULTS. Os enunciados mais uma vez foram direcionados pelos experts em educação, programação e design, em ações que objetivavam favorecer a percepção dos novatos (educandos) sobre seu próprio cotidiano campesino, mas que favoreceram, também, conhecimento sobre essas rotinas pelos experts, que afetariam o sentido dos próprios pesquisadores sobre os territórios rurais. Nessa direção, é interessante que o jogo entre experts e novatos alterne-se, já que, sobre territórios rurais, os educandos que vivenciam esses territórios é que possuem alguma expertise na prática, sendo os pesquisadores (educadores, programadores e designers na $\mathrm{CP}$ ) os iniciantes/novatos nesse momento, pois são sujeitos constituídos por significações marcadamente urbanas.

A entrada dos técnicos agrícolas tornou-se uma necessidade, pois os pesquisadores, vindos dos centros urbanos, se colocaram no lugar do "não saber" sobre o rural, não favorecendo uma mediação precisa aos artefatos digitais para educação do campo. Os técnicos possuíam conhecimentos científicos em diálogo com os territórios rurais, ricos em vivências para produção de sentidos, tornando-se uma participação autoral fundamental nas etapas seguintes. Nas duas escolas emergiram enunciados dos experts em educação, programação e design que indicavam a importância dessa aproximação com os cotidianos, para o desenvolvimento dos artefatos digitais nas próximas etapas, bem como marcavam algumas relações entre a atividade de história em quadrinhos, as narrativas e o processo de desenvolvimento de storyboards no processo de desenvolvimento de jogos digitais.

Delimitação Conceitual - Nesta fase é feita a definição da temática do artefato digital educacional. Parte-se dos problemas e situações cotidianas identificados na etapa de Imersão, e se constrói um entrelace entre os conhecimentos prévios dos educandos, construídos com seus responsáveis, no cultivo da terra em suas parcelas de terra, com os conteúdos científicos e curriculares. Tal entrelace é feito considerando o fortalecimento da educação do campo e tem forte presença dos técnicos agrícolas do município que, nesta etapa, fazem visitas com os educandos à horta e à composteira da escola.

Ideação - Na fase de ideação, a partir da definição do conteúdo a ser trabalhado, foram evidenciados alguns enunciados dos novatos (educandos) que não encontravam respostas seguras por parte dos experts em programação e design (pesquisadores). Firmou-se a presença contínua de especialistas nos conteúdos apontados, sendo este espaço simbólico ocupado pelos técnicos agrícolas do município que já realizavam ações educativas nas escolas, independentes do DEMULTS. Os técnicos se voluntariaram e participaram com enunciados que valorizaram o debate rural-urbano, o vínculo com práticas sustentáveis em territórios campesinos e conhecimentos sobre sustentabilidade ambiental, agroecologia e agricultura familiar. Os enunciados dos novatos começaram a ganhar mais autonomia nesta fase, e favoreceu sua relação de horizontalidade com os enunciados dos experts (em educação, design e programação, mas também dos técnicos agrícolas). Os novatos começaram a conceber escolhas sobre os artefatos digitais que seriam desenvolvidos, com esboços que indicavam a preferência pelo desenvolvimento de jogos digitais, exceto uma das equipes, na escola B, que optou pelo desenvolvimento de um aplicativo.

Produção - Devido à falta de estrutura nas escolas para realização da fase de Produção propriamente dita, ambas as turmas tiveram que realizar translados, nos dias de encontro com o grupo do DEMULTS, para que as atividades de desenvolvimento acontecessem em um 
espaço público informatizado, com computadores e internet, mas localizado no centro da cidade, com contornos urbanos nítidos. Porém, foi a solução indicada pela secretaria de educação e coordenadoras das escolas, para a realização das atividades. Nos enunciados dos experts, evidenciam-se as faltas de condições das escolas do campo, e necessidade de equipamentos. Nos enunciados dos novatos, aparecem suas motivações por realizar ações em computadores, mediadas por artefatos digitais, como se finalmente o que esperavam do projeto pudesse se realizar.

Conforme a afinidade com o tema e com os outros educandos, os grupos organizavam-se para a criação dos artefatos digitais. A turma da Escola A se dividiu em duas equipes para a criação de dois jogos digitais e a turma da escola B se dividiu em quatro grupos, para a criação de três jogos digitais e um aplicativo. Para os grupos que optaram por construir jogos digitais, foi apresentado o software Scratch, e para o grupo que optou pelo desenvolvimento de um aplicativo, foi apresentado o software MIT App Inventor, com enunciados direcionados pelos experts em programação, principalmente. Cada software foi marcado nas configurações contextuais com enunciados que reforçam a prática de PUF, com emergência de enunciados sobre suas funcionalidades, as quais foram sendo aprendidas em situações de uso concretas, durante a prática de desenvolvimento, como em uma CP.

Após a apresentação de algumas possibilidades oferecidas pelos softwares, os novatos foram incentivadas/os a encontrar soluções para materializar digitalmente as ideias discutidas e registradas anteriormente em seus registros, no papel. A articulação educacional dos artefatos digitais (jogos e aplicativo) que estavam desenvolvendo, com os territórios do campo, também foi estabelecida na $\mathrm{CP}$, realçando nos enunciados o teor educacional dos produtos, a serem usados por eles e por outros educandos de escolas do campo. Foram evidenciados vários enunciados que indicaram aprendizagem e que emergiram regularmente em todos os encontros desta fase, para soluções de problemas conjuntos, na colaboração entre experts e novatos, e dos novatos entre si. Houve uma descentralização dos enunciados dos experts, regular nos primeiros encontros (fase de Apresentação e Ideação), com a participação cada vez mais proeminente dos novatos (educandos), que transformavam sua participação periférica legítima em direção a um possível centro da CP. As configurações contextuais desta fase favoreceram a emergência de enunciados que congregaram significados de práticas de desenvolvedores com significados dos contextos campesinos, articulados entre si.

Nos enunciados que emergiram desta fase, na escola A, houve marcas de vozes nos enunciados dos novatos que remetiam a interesses do agronegócio, em contraposição a vozes da agroecologia ou agricultura familiar, estas últimas muito evidenciadas nos enunciados dos técnicos. Apesar das mediações dos técnicos, das coordenadoras da escola (que por vezes contribuíram como experts nos conteúdos de educação do campo), dos pesquisadores e mesmo de outros sociais acessados in loco em leituras e pesquisas científicas na internet, para que os novatos alinhassem seus discursos às vozes da educação do campo, não foi evidenciada uma transformação subjetiva nos educandos que se posicionaram alinhados ao discurso hegemônico. De todo modo, nos artefatos digitais educacionais, frutos dessas atividades, os educandos implementaram funcionalidades com convergência às vozes dos contextos campesinos.

Testes - Esta fase ainda não aconteceu, mas há um potencial dialógico, que pode ser pressuposto, com algumas continuidades/descontinuidades das fases anteriores. Com vasta produção de sentido tanto sobre territórios campesinos, como sobre processos de 
programação e design, com resolução de problemas e soluções computacionais, os artefatos digitais foram convergentes com diretrizes da educação do campo, embora algumas temáticas façam relação também com vozes dos engenhos de cana de açúcar, presentes na região onde se situam as escolas.

Os artefatos digitais projetados contemplam os seguintes eixos enunciativos: $\mathrm{Na}$ escola A, dois jogos - um ocorre no período da safra de cana-de-açúcar, em que o jogador é um trabalhador que corta cana para uma usina da cidade, mas questiona seu salário e possui uma horta em seu terreno, na qual ensina sua filha sobre o cultivo agroecológico de hortaliças; e outro ocorre durante a entressafra, em que o jogador tira seu sustento com plantio de horta orgânica; na Escola B, três jogos e um aplicativo para smartphone - os jogos versam sobre coleta seletiva de resíduos sólidos, bem como a reciclagem de tais resíduos, inclusive com foco em compostagem; enquanto o aplicativo apresenta tutoriais e textos produzidos pelos educandos sobre horta agroecológica.

\section{Considerações finais}

Apresentamos resultados iniciais do DEMULTS-Campo, que evidenciam aprendizagem em escolas de territórios rurais, nas regularidades das ações dos educandos, ao apropriarem-se de práticas discursivas de equipes de desenvolvimento de artefatos digitais educacionais. Esses artefatos, direcionados a um público de escolas do campo do qual fazem parte os educandos, são frutos de um movimento dialógico encapsulado nas marcas enunciativas dos produtos desenvolvidos.

O processo interativo, que fundamenta o DEMULTS, permite que os participantes do processo - novatos e experts - compartilhem significados, troquem informações acerca das ferramentas necessárias, alternem os papéis, colaborem na resolução de problemas comuns e tenham acesso a elementos culturais de territórios diversos, favorecendo a criação de artefatos digitais educacionais para os povos do campo. A apropriação recíproca de significados originou transformações na percepção sobre os territórios rurais, convergindo com as diretrizes da educação do campo, pela relação intrínseca entre as identidades dos sujeitos do campo e as identidades de desenvolvedores de tecnologias digitais. Para completar o fluxo dialógico ininterrupto, diversas práticas de uso dos artefatos desenvolvidos neste ciclo precisam ser investigadas, para maior compreensão sobre seus limites e possibilidades discursivas.

\section{Referências}

Baranauskas, M. C. C. (2013) "O modelo semioparticipativo do design", In: Baranauskas, M. C. C.; Martins, M. C; Valente, J. A. (orgs). Codesign de redes digitais: tecnologia e educação a serviço da inclusão social. Porto Alegre, Penso, p. 38-66

Bauman, Z. (2005) Identidade. Rio de Janeiro, Jorge Zahar Ed, 2005

Bakhtin, M. (2004) Marxismo e Filosofia da Linguagem $11^{\text {a }}$ Edição. São Paulo: HUCITEC.

Caldart, R. S.; Cerioli, P. R; Kolling, E. J. (2002) Educação do campo: identidade e políticas públicas. Brasília, articulação nacional Por uma Educação do Campo.

Castells, M. (1999) A sociedade em rede. São Paulo: Paz e Terra. 
Falcão, T. P.; Oliveira, G. S.; Peres, F. M. A; Morais, D. C. S. (2017) “Design Participativo de Jogos Digitais Educacionais por Adolescentes Imersos em uma Comunidade de Prática", In: Revista de Sistemas e Computação, Salvador, v. 7, n. 2, p. 189-205.

Fernandes, B. M. (2006) "Os campos da Pesquisa em Educação do Campo: espaço e território como categorias essenciais", In: MOLINA, M. C. (Org.). Educação do Campo e Pesquisa: questões para reflexão. Ministério do Desenvolvimento Agrário: Brasília. p.27-39.

Goodwin, C. (2000) Action and embodiment within situated human interaction. Journal of Pragmatics, 32, 1489-1522.

Hall, S. (2011) A identidade cultural na pós-modernidade. DP\&A ed.

IBGE - Instituto Brasileiro de Geografia e Estatística. (2018) PNAD Contínua - TIC 2018: Internet chega a $79,1 \%$ dos domicílios do país. Disponível em: $<$ https://agenciadenoticias.ibge.gov.br/agencia-sala-de-imprensa/2013-agencia-denoticias/releases/27515-pnad-continua-tic-2018-internet-chega-a-79-1-dos-domiciliosdo-pais>. Acesso em: 26 de julho de 2020.

Leal, O. (2018) A importância da tecnologia na educação da escola do campo. Monografia (especialização) - Universidade Federal do Paraná.

Lieberman, H Paternò, F.; Wulf, V. (2006) End User Development. The Netherlands, Springer, 1 ed.

Medina, L. (2013) El Análisis Dialógico del Discurso: Analizar el discurso sin olvidar el discurso. En Canales, M. (Coord.). Escucha de la escucha. Análisis e interpretación en la investigación cualitativa p. 295-317. Santiago: Universidad de Chile.

Molina, M. C (2008) "A constitucionalidade e a justicibilidade do direito à educação dos povos do campo", In. Santos, C. A. (org). Educação do campo: campo - políticas públicas - educação. Brasília, Incra, MDA.

Munarim, I (2014) As tecnologias digitais nas escolas do campo: contextos, desafios possibilidades. Tese (doutorado) - Universidade Federal de Santa Catarina, Centro de Ciências da Educação, Programa de Pós-Graduação em Educação, Florianópolis.

Peres, F. M. A.; Falcão, T. P.; Morais, D. C. S.; Oliveira, G. S. "DEMULTS: Desenvolvimento Educacional de Multimídias Sustentáveis", In: Meira, L. Blikstein, P. (Orgs.) Ludicidade, jogos digitais e gamificação na aprendizagem. Porto Alegre: Penso, 2020 .

Santos, C. F. (2013) O "aprender a aprender" na formação dos professores do campo. Campinas, S.P: Autores associados; Vitória da Conquista, BA: Edições UESB.

Thiollent, M. (2004) Metodologia da pesquisa-ação. São Paulo: Cortez, 2004.

Vigotski, L. S. (2001) A construção do pensamento e da linguagem. São Paulo: Martins Fontes.

Wenger, E (1998) Communities of practice: learning, meaning, and identity. Cambridge, Mass: Cambridge University, 1998. 